\title{
Biomarker Driven Cancer Therapeutics: Existing Tools and Remaining Gaps
}

\author{
Sasi Shanmugam Senga ${ }^{*}$, Jemma Arakelyan² \\ ${ }^{1}$ Division of Neuroscience, Australian National University, Canberra, Australia \\ ${ }^{2}$ Department of Oncology, Yerevan State Medical University, Yerevan, Armenia \\ Email: *authordrsashi@gmail.com, jemmaarakelyan93@gmail.com
}

How to cite this paper: Senga, S.S. and Arakelyan, J. (2020) Biomarker Driven Cancer Therapeutics: Existing Tools and Remaining Gaps. Open Access Library Journal, 7: e6556. https://doi.org/10.4236/oalib.1106556

Received: June 24, 2020

Accepted: July 28, 2020

Published: July 31, 2020

Copyright $\odot 2020$ by author(s) and Open Access Library Inc.

This work is licensed under the Creative Commons Attribution International License (CC BY 4.0).

http://creativecommons.org/licenses/by/4.0/ (c) (i) Open Access

\begin{abstract}
Advancements in technology such as proteomics, genomics have led to the concept of personalized medicine wherein the integration of biomarkers into clinic directs cancer therapeutics. Traditional staging has a stochastic element which can only predict the outcome without actual consideration of intrapatient heterogeneity. In this review, we will look at the biomarkers that prove to be valuable tools for the personalization of cancer therapeutics among lung and breast cancer patients.
\end{abstract}

\section{Subject Areas}

Oncology

\section{Keywords}

Cancer Biomarkers, Breast Cancer, Lung Cancer

\section{Introduction}

Breast cancer is one of the most common cancers worldwide and has affected 2.1 million women in the year 2018 alone [1]. While conventional tumour size, lymph node status, and presence or absence of metastasis can direct therapeutics and prognosis, biomarkers give a better picture of an individual's tumour to use targeted therapies.

Breast tumours typically involve multiple driver mutations and evolve over time and specific genomic signatures such as ones arising from mismatch repairs can be useful biomarkers in aiding diagnosis as well as making treatment decisions. A gain of function mutation that leads to an excess of an oncoprotein is a viable target for example amplification of human epidermal growth factor receptor 2 (HER2) than a loss of function (Figure 1). 


\section{Breast Cancer subtypes based on histology and IHC}
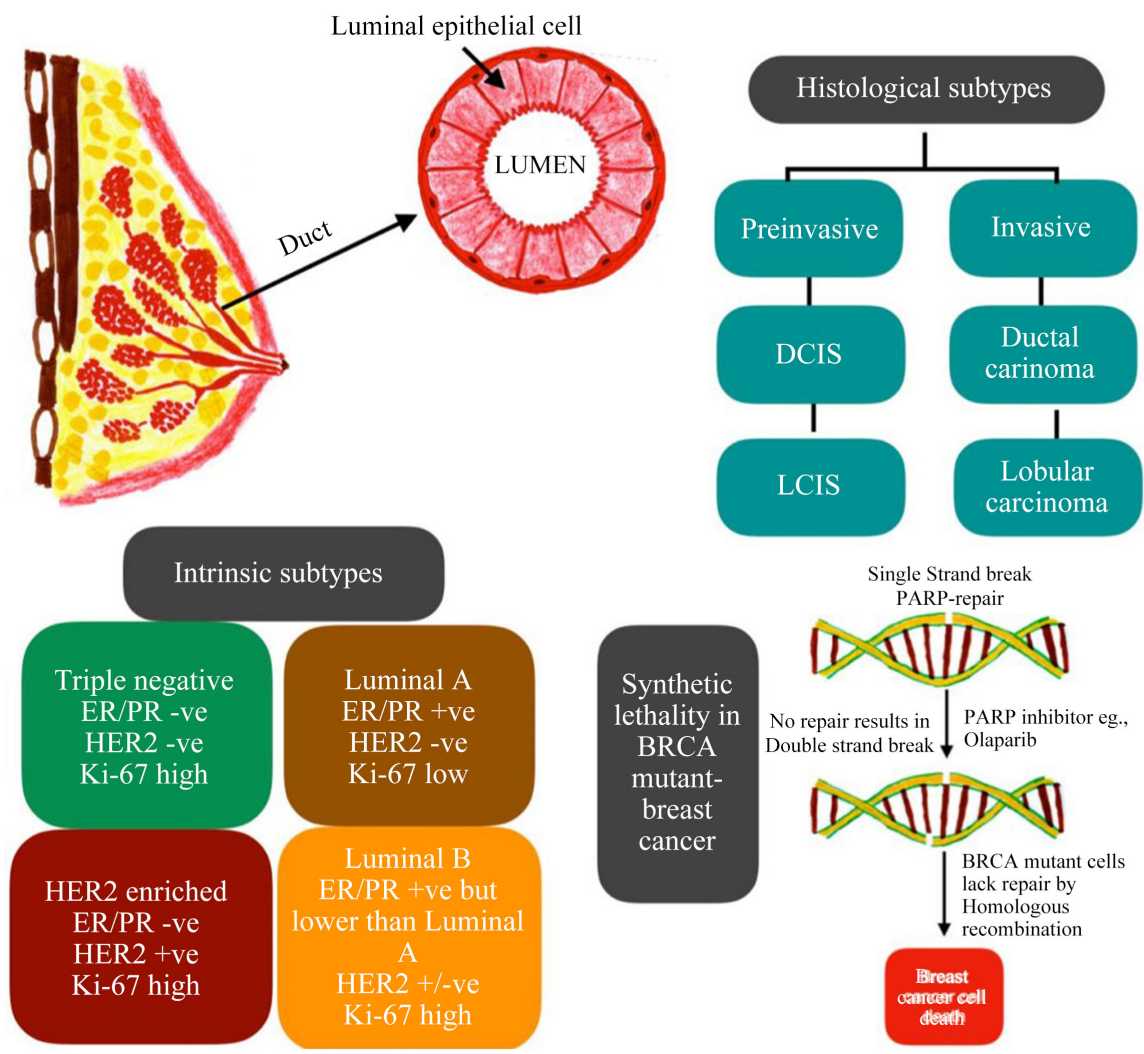

Figure 1. Drawn based on Sims et al:; 2007 [24]. Breast Cancer subtypes based on histology and IHC. DCIS-Ductal carcinoma in situ; LCIS-Lobular carcinoma in situ; ER-Estrogen receptor; PR-Progesterone receptor; Ki-67 Proliferation index. BRCA can serve as a biomarker to identify patients who will benefit from PARP inhibitors.

\section{HER2neu receptors}

Breast cancers that express HER2 were shown to be highly invasive with features of focal progression and often metastasize to distant organs as such it carried a poor prognosis [2]. It is a pivotal invasive biomarker linked to aggressive disease, and often resistant to chemotherapeutic regimens other than anthracyclines and paclitaxel [3]. But in 1998, following the approval of Trastuzumab [4], the odds of survival has changed drastically along with additional targeted therapies such as Trastuzumab emtansine, Pertuzumab, and lapatinib that have since evolved. HER2 positive breast tumours now carry a much better survival owing to the identification of the biomarker signifying the pivotal nature of biomarkers in cancer therapeutics.

\section{Estrogen receptors (ER)}

A vast majority of breast cancers express ER- $\alpha$ positivity. The degree of positivity (score of $0-5)$ and staining intensity (0 - 3) [5] varies, but even in cases with negative results involving tubular or lobular carcinoma, the results must be reconfirmed. As ER positivity is associated with a highly favourable prognosis with the usage of hormonal therapy e.g., Tamoxifen to block estrogen can result 
in remission and in ductal carcinoma in situ the recurrence drops by $50 \%$ in ER positive cases. Resistance a few years following hormonal therapy is a major challenge, one study has shown rewiring critical regulatory regions via methylation leads to resistance [6].

\section{Progesterone receptor (PR)}

$\mathrm{PR}$ is positive in about $70 \%$ of invasive ductal carcinoma, they are regulated by ER- $\alpha$. PR has been shown to be involved in the reprogramming of ER, acting as a brake of proliferation in ER positive breast cancers [7]. Recurrence is higher in ER positive, PR negative cases than ER positive and PR positive ones. The value of PR positivity in the choice of endocrine treatment has not been proven but a study has shown combined endocrine receptor (CER) score which takes account of both ER and PR status to be a better predictor of disease-free survival than mere IHC of receptor status which will only predict the response to hormonal treatment [8] (Figure 2).

\section{Ki-67}

IHC assessment of Ki-67 is a measure of proliferative activity. Although the cut-off points are not concordant among various labs, a high proliferative index is $\mathrm{Ki}-67$ levels above 20 regardless of assessment method generally carries a poor prognosis [9].

\section{IHC4 + C score}

It incorporates ER, PR status, Ki-67, plus clinicopathological features such as tumour size, nodal status, and grade. A study has shown IHC4 + C can eliminate unwarranted chemotherapy in the adjuvant setting in hormone-positive patients [9].

Depicts breast cancer biomarkers in clinical use and those that are upcoming

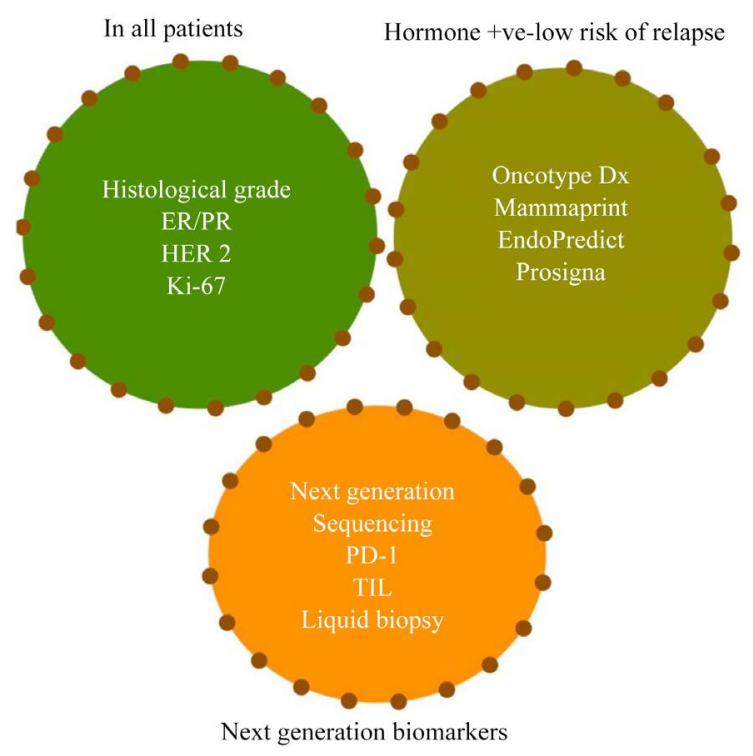

Figure 2. Drawn based on Sims et al., 2007 [24]. TIL-tumour infiltrating lymphocytes; PD-1-Programmed death-1. 


\section{Mammaprint}

Mammaprint a 70 gene expression assay that quantifies gene expression based on DNA microarray, divides breast carcinoma into high risk and low-risk subtypes.

MINDACT trial by utilizing Mammaprint showed that about $46 \%$ of women who were categorized to be of high risk clinically may not benefit from adjuvant chemotherapy if they have a low genomic risk, it led to ASCO approval to give patients with hormone positive, HER-2 negative, 1 to 3 positive lymph nodes with high clinical risk the option to forego adjuvant chemotherapy [10]. An important question is why only hormone positive? Why not hormone negative cancers? The reason is the discriminatory power of Mammaprint is driven by proliferation markers which are unanimously high in ER negative tumours.

\section{Oncotype Dx}

Oncotype Dx which tests 21 gene expression has been optimized for use in formalin-fixed tissue. It gives a recurrence score categorizing tumours into low, intermediate and high-risk groups, as per the 2016 ASCO guidelines it is useful in a decision over adjuvant chemotherapy only in node-negative disease [11].

\section{Prosigna (PAM 50)}

Utilizes 50 gene signatures to predict the 10-year distant metastasis-free survival in women with node-positive disease who are postmenopausal and hormone-positive. It divides the risk of recurrence into low (score $<40$ ), intermediate (score 40 - 60) and high (score $>60$ ) risk groups [12].

\section{Endopredict (EP)}

Based on the expression of 12 genes using RT-PCR (Reverse transcription-polymerase chain reaction) to calculate the risk of recurrence, along with tumour size and nodal status gives a comprehensive risk score and enables stratification of ER positive and HER 2 negative early-stage patients to identify low-risk groups who can be treated with endocrine therapy alone with excellent prognosis without chemotherapy and those who may not need extended adjuvant hormonal therapy [13].

\section{Lung Cancer}

Non-Small cell lung cancer (NSCLC) has a plethora of biomarkers that are routinely used clinically to assess disease risk and guide treatment decisions. Despite advancement in therapy, the 5-year survival rate is about 15\% [14], due to the presence of advanced disease at the time of initial diagnosis which necessitates early diagnosis (Table 1 ).

\section{MicroRNA miR-33a-5p and miR-128-3p}

A study has reported the level of miR-33a-5p and miR-128-3p to be low in the whole blood of lung cancer patients and has been proposed to be used as a biomarker for early diagnosis of lung cancer. miR-33a-5p has been shown to inhibit epithelial to mesenchymal transition in NSCLC and can serve as a prognostic factor [15] [16].

\section{Blood tumour mutational burden}


In a less invasive approach to measure tumour mutational burden (TMB) plasma cell-free DNA has been used instead of DNA from tumour tissue to determine lung cancer patients who will benefit from immune checkpoint inhibitors [17], especially checkpoint inhibitors like Pembrolizumab are of immense value to NSCLC patients with metastatic disease who otherwise had a 5 year OS rate of 5.5\% [18]. PD-L1 expression-tumour proportion score (TPS) remains the standard biomarker to identify patients who will benefit from immune checkpoint inhibitors despite its shortcomings such as the discordance of PD-L1 expression between primary and metastatic lesion (Figure 3).

Table 1. Depicts lung cancer biomarkers.

\begin{tabular}{ccccc}
\hline Biomarker & $\begin{array}{c}\text { Squamous cell } \\
\text { carcinoma }\end{array}$ & Adenocarcinoma & $\begin{array}{c}\text { Small cell Lung } \\
\text { cancer }\end{array}$ & $\begin{array}{c}\text { Large cell } \\
\text { neuroendocrine } \\
\text { carcinoma }\end{array}$ \\
\hline CEA & $\uparrow$ & $\uparrow$ & $\uparrow$ & $\uparrow$ \\
PSF3 & - & $\uparrow \uparrow$ & - & - \\
Pro GRP & - & - & $\uparrow \uparrow$ & - \\
SCCA & $\uparrow \uparrow$ & - & - & - \\
NSE & - & - & $\uparrow \uparrow$ & - \\
CYFRA 21-1 & $\uparrow \uparrow$ & - & & $\uparrow \uparrow$ \\
SST & - & - & - & - \\
\hline
\end{tabular}

Adapted based on (Hanash et al., 2018) [25]. CEA-carcinoembryonic antigen; SCCA: Squamos cell carcinoma antigen; NSE: Neuron-specific enolase; SST: Somatostatin.

\section{Systemic therapy for advanced NSCLC}

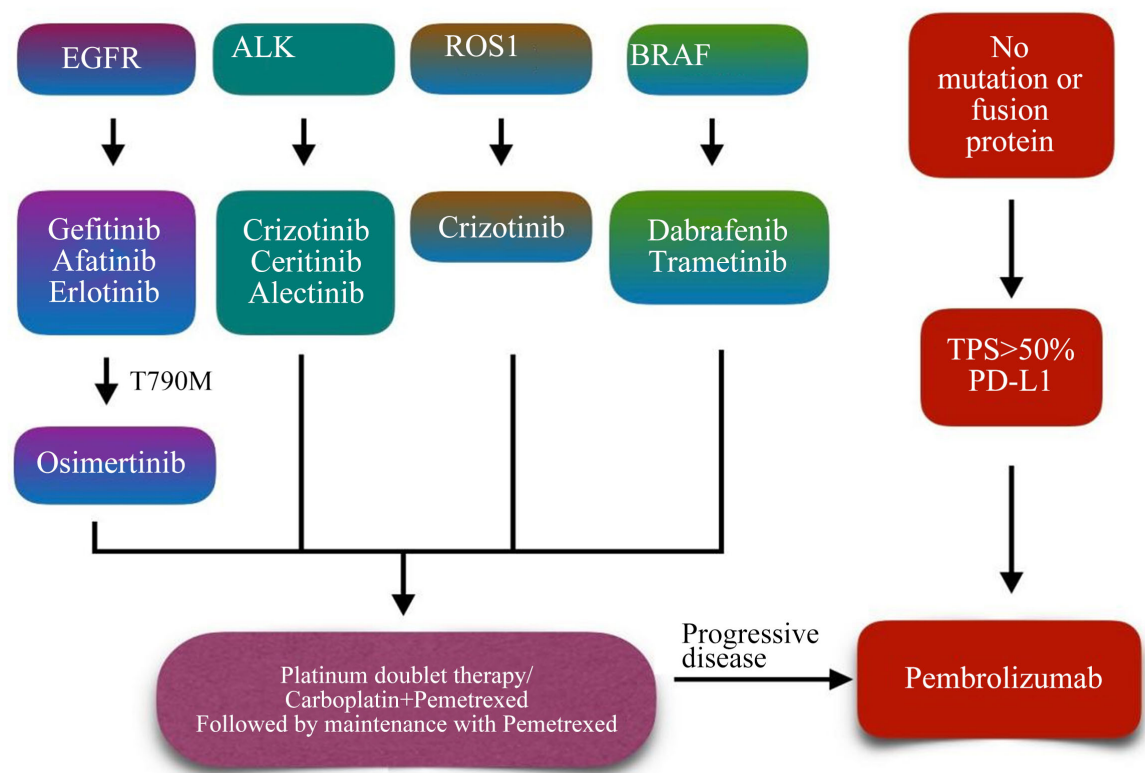

Figure 3. Adapted from Melosky et al; 2018 [26]. Management of NSCLC patients using biomarkers of mutation/fusion proteins; TPS-tumour proportion score. 
A study has shown that treatment with Pembrolizumab resulted in a 5 year OS rate $>25 \%$ in NSCLC patients with advanced disease who had TPS $>50 \%$ [18]. Patients with advanced lung adenocarcinomas are usually tested for ROS1 and $A L K$ rearrangements, as well as EGFR and BRAF mutations as their progression-free survival (PFS), increases with targeted therapy.

\section{Epidermal growth factor receptor (EGFR)}

$E G F R$ mutations generally found in non-smokers with adenocarcinomas possessing lepidic features responds to tyrosine kinase inhibitors (TKI) such as Gefitinib, Afatinib, and Erlotinib. It is important to check for 1790 mutation in patients who develop resistance to TKI as they will benefit from Osimertinib [19].

\section{Anaplastic lymphoma kinase ( $A L K)$}

The $E M L 4-A L K$ fusion is found in a subset of lung adenocarcinoma patients who show a much better response, median PFS 10.9 months with $A L K$ inhibitor Crizotinib vs 7 months with conventional chemotherapy [20].

Similarly, Crizotinib has shown to benefit patients with ROS1 rearrangements with a response rate of up to 80 [21].

\section{$B R A F$}

Patients with BRAF V600E mutations are generally smokers and respond poorly to platinum-based chemotherapeutic regimens and carry a poor prognosis but they benefit from $B R A F$ inhibitors such as Vemurafenib and Dabrafenib [22].

\section{Neurotrophic receptor tyrosine kinase 1 (NTRK1)}

In $3 \%$ of lung adenocarcinoma patients who harbor $N T R K$ fusion a phase 1 studies has reported the benefit of NTRK inhibitor, Entrectinib [23].

The exact histological subtyping is pivotal to let patients benefit from such targeted therapies. Diagnostic biomarkers such as thyroid transcription factor (TTF1) and Napsin A are useful in distinguishing poorly differentiated adenocarcinoma from squamous cell carcinoma as it can be quite challenging using only microscopy [19].

\section{Prospective}

Future studies must focus on biomarkers of cancer prevention and recurrence. ATP citrate lyase cytoplasmic (ACLY) a metabolic enzyme involved in the conversion of mitochondrial-derived citrate into acetyl CoA, a key link between aerobic glycolysis and fatty acid synthesis is gaining traction as an independent predictor of breast cancer recurrence. Increased ACLY has been attributed to poor prognosis both in lung cancer [26] as well as breast cancer [27].

There are a whole array of novel biomarkers along the pipeline, and analysis of circulating free DNA (cfDNA) via non-invasive liquid biopsies confers the advantage of repeated sample collection during the course of treatment enabling detection of new genetic mutations that may emerge such as the EGFR Mutation Test v2 (Cobas) which was approved by the FDA in 2016. Even gap junction proteins which are sensitive to injury or disease has been shown to be a potential 
biomarker in lung cancers [27], detection of Gap junction beta-4 protein via liquid biopsy has been shown to serve as a novel biomarker to predict chemoresistance in lung cancer [25].

\section{Conclusions}

Administration of Gefitinib to unselected NSCLC patients did not show any improvement in survival but when the same was administered to those carrying an EGFR mutation resulted in a higher response rate signifying the power of biomarker in making therapeutic decisions based on a patient's specific tumour feature.

Herceptin has revolutionized the odds for HER2 positive patients who earlier used to carry a very poor prognosis which reiterates the significance of biomarkers as a tool for refining the classification and prognosis of cancer.

As the famous quote by Samuel Coleridge "Water, water, everywhere, Nor any drop to drink", despite the abundance of biomarkers their translation to the clinic has several challenges such as a targeted therapy may be beneficial to the patient but it must also be one that is required continuously for a long-term in order to be a commercial success. Despite evidence of tremendous benefit in targeted therapies based on such biomarkers, their integration from bench to clinic has been challenging. The plethora of promising biomarkers arising from the omics era will change the future of cancer therapeutics from "one size fits all" to individualization.

\section{Acknowledgements}

In loving memory of my mother Kalavathi who shaped me as a responsible physician and human being.

\section{Conflicts of Interest}

The authors declare no conflicts of interest regarding the publication of this paper.

\section{References}

[1] Bray, F., Ferlay, J., Soerjomataram, I., Siegel, R., Torre, L. and Jemal, A. (2018) Global Cancer Statistics 2018: GLOBOCAN Estimates of Incidence and Mortality Worldwide for 36 Cancers in 185 Countries. CA: A Cancer Journal for Clinicians, 68, 394-424. https://doi.org/10.3322/caac.21492

[2] Vaught, D., Stanford, J., Young, C., Hicks, D., Wheeler, F., Rinehart, C., Sanchez, V., Koland, J., Muller, W., Arteaga, C. and Cook, R. (2012) HER3 Is Required for HER2-Induced Preneoplastic Changes to the Breast Epithelium and Tumor Formation. Cancer Research, 72, 2672-2682. https://doi.org/10.1158/0008-5472.CAN-11-3594

[3] Hanna, W., Slodkowska, E., Lu, F., Nafisi, H. and Nofech-Mozes, S. (2017) Comparative Analysis of Human Epidermal Growth Factor Receptor 2 Testing in Breast Cancer According to 2007 and 2013 American Society of Clinical Oncology/College of American Pathologists Guideline Recommendations. Journal of Clinical Oncol- 
ogy, 35, 3039-3045. https://doi.org/10.1200/JCO.2016.70.5319

[4] Slamon, D., Leyland-Jones, B., Shak, S., Fuchs, H., Paton, V., Bajamonde, A., Fleming, T., Eiermann, W., Wolter, J., Pegram, M., Baselga, J. and Norton, L. (2001) Use of Chemotherapy plus a Monoclonal Antibody against HER2 for Metastatic Breast Cancer That Overexpresses HER2. New England Journal of Medicine, 344, 783-792. https://doi.org/10.1056/NEJM200103153441101

[5] Allred, D. (2010) Issues and Updates: Evaluating Estrogen Receptor- $\alpha$, Progesterone Receptor, and HER2 in Breast Cancer. Modern Pathology, 23, S52-S59. https://doi.org/10.1038/modpathol.2010.55

[6] Achinger-Kawecka, J., Valdes-Mora, F., Luu, P., Giles, K., Caldon, C., Qu, W., Nair, S., Soto, S., Locke, W., Yeo-Teh, N., Gould, C., Du, Q., Smith, G., Ramos, I., Fernandez, K., Hoon, D., Gee, J., Stirzaker, C. and Clark, S. (2020) Epigenetic Reprogramming at Estrogen-Receptor Binding Sites Alters 3D Chromatin Landscape in Endocrine-Resistant Breast Cancer. Nature Communications, 11, Article No. 320. https://doi.org/10.1038/s41467-019-14098-X

[7] Mohammed, H., Russell, I., Stark, R., Rueda, O., Hickey, T., Tarulli, G., Serandour, A., Birrell, S., Bruna, A., Saadi, A., Menon, S., Hadfield, J., Pugh, M., Raj, G., Brown, G., D’Santos, C., Robinson, J., Silva, G., Launchbury, R., Perou, C., Stingl, J., Caldas, C., Tilley, W. and Carroll, J. (2015) Progesterone Receptor Modulates ER $\alpha$ Action in Breast Cancer. Nature, 523, 313-317. https://doi.org/10.1038/nature14583

[8] Campbell, E., Tesson, M., Doogan, F., Mohammed, Z., Mallon, E. and Edwards, J. (2016) The Combined Endocrine Receptor in Breast Cancer, a Novel Approach to Traditional Hormone Receptor Interpretation and a Better Discriminator of Outcome than ER and PR Alone. British Journal of Cancer, 115, 967-973. https://doi.org/10.1038/bjc.2016.206

[9] Yeo, B., Zabaglo, L., Hills, M., Dodson, A., Smith, I. and Dowsett, M. (2015) Clinical Utility of the IHC4 + C Score in Oestrogen Receptor-Positive Early Breast Cancer: A Prospective Decision Impact Study. British Journal of Cancer, 113, 390-395. https://doi.org/10.1038/bjc.2015.222

[10] Krop, I., Ismaila, N., Andre, F., Bast, R., Barlow, W., Collyar, D., Hammond, M., Kuderer, N., Liu, M., Mennel, R., Van Poznak, C., Wolff, A. and Stearns, V. (2017) Use of Biomarkers to Guide Decisions on Adjuvant Systemic Therapy for Women with Early-Stage Invasive Breast Cancer: American Society of Clinical Oncology Clinical Practice Guideline Focused Update. Journal of Clinical Oncology, 35, 2838-2847. https://doi.org/10.1200/JCO.2017.74.0472

[11] Harris, L., Ismaila, N., McShane, L., Andre, F., Collyar, D., Gonzalez-Angulo, A., Hammond, E., Kuderer, N., Liu, M., Mennel, R., Van Poznak, C., Bast, R. and Hayes, D. (2016) Use of Biomarkers to Guide Decisions on Adjuvant Systemic Therapy for Women with Early-Stage Invasive Breast Cancer: American Society of Clinical Oncology Clinical Practice Guideline. Journal of Clinical Oncology, 34, 1134-1150. https://doi.org/10.1200/JCO.2015.65.2289

[12] Martín, M., González-Rivera, M., Morales, S., de la Haba-Rodriguez, J., González-Cortijo, L., Manso, L., Albanell, J., González-Martín, A., González, S., Arcusa, A., de la Cruz-Merino, L., Rojo, F., Vidal, M., Galván, P., Aguirre, E., Morales, C., Ferree, S., Pompilio, K., Casas, M., Caballero, R., Goicoechea, U., Carrasco, E., Michalopoulos, S., Hornberger, J. and Prat, A. (2015) Prospective Study of the Impact of the Prosigna Assay on Adjuvant Clinical Decision-Making in Unselected Patients with Estrogen Receptor Positive, Human Epidermal Growth Factor Receptor Negative, Node Negative Early-Stage Breast Cancer. Current Medical Research and Opinion, 31, 1129-1137. https://doi.org/10.1185/03007995.2015.1037730 
[13] Dubsky, P., Filipits, M., Jakesz, R., Rudas, M., Singer, C., Greil, R., Dietze, O., Luisser, I., Klug, E., Sedivy, R., Bachner, M., Mayr, D., Schmidt, M., Gehrmann, M., Petry, C., Weber, K., Kronenwett, R., Brase, J. and Gnant, M. (2013) EndoPredict Improves the Prognostic Classification Derived from Common Clinical Guidelines in ER-Positive, HER2-Negative Early Breast Cancer. Annals of Oncology, 24, 640-647. https://doi.org/10.1093/annonc/mds334

[14] Siegel, R., Miller, K. and Jemal, A. (2018) Cancer Statistics, 2018. CA: A Cancer Journal for Clinicians, 68, 7-30. https://doi.org/10.3322/caac.21442

[15] .Pan, J., Zhou, C., Zhao, X., He, J., Tian, H., Shen, W., Han, Y., Chen, J., Fang, S., Meng, X., Jin, X. and Gong, Z. (2018) A Two-miRNA Signature (miR-33a-5p and miR-128-3p) in Whole Blood as Potential Biomarker for Early Diagnosis of Lung Cancer. Scientific Reports, 8, Article No. 16699. https://doi.org/10.1038/s41598-018-35139-3

[16] Yang, L., Yang, J., Li, J., Shen, X., Le, Y., Zhou, C., Wang, S., Zhang, S., Xu, D. and Gong, Z. (2015) MircoRNA-33a Inhibits Epithelial-to-Mesenchymal Transition and Metastasis and Could Be a Prognostic Marker in Non-Small Cell Lung Cancer. Scientific Reports, 5, Article No. 13677. https://doi.org/10.1038/srep13677

[17] Wang, Z., Duan, J., Cai, S., Han, M., Dong, H., Zhao, J., Zhu, B., Wang, S., Zhuo, M., Sun, J., Wang, Q., Bai,H., Han, J., Tian, Y., Lu, J., Xu, T., Zhao, X., Wang, G., Cao, X., Li, F., Wang, D., Chen, Y., Bai, Y., Zhao, J., Zhao, Z., Zhang, Y., Xiong, L., He, J., Gao, S. and Wang, J. (2019) Assessment of Blood Tumor Mutational Burden as a Potential Biomarker for Immunotherapy in Patients with Non-Small Cell Lung Cancer with Use of a Next-Generation Sequencing Cancer Gene Panel. JAMA Oncology, 5, 696. https://doi.org/10.1001/jamaoncol.2018.7098

[18] Garon, E., Hellmann, M., Rizvi, N., Carcereny, E., Leighl, N., Ahn, M., Eder, J., Balmanoukian, A., Aggarwal, C., Horn, L., Patnaik, A., Gubens, M., Ramalingam, S., Felip, E., Goldman, J., Scalzo, C., Jensen, E., Kush, D. and Hui, R. (2019) Five-Year Overall Survival for Patients with Advanced Non-Small-Cell Lung Cancer Treated with Pembrolizumab: Results from the Phase I KEYNOTE-001 Study. Journal of Clinical Oncology, 37, 2518-2527. https://doi.org/10.1200/JCO.19.00934

[19] Inamura, K. (2018) Update on Immunohistochemistry for the Diagnosis of Lung Cancer. Cancers, 10, 72. https://doi.org/10.3390/cancers10030072

[20] Solomon, B., Mok, T., Kim, D., Wu, Y., Nakagawa, K., Mekhail, T., Felip, E., Cappuzzo, F., Paolini, J., Usari, T., Iyer, S., Reisman, A., Wilner, K., Tursi, J. and Blackhall, F. (2014) First-Line Crizotinib versus Chemotherapy in ALK-Positive Lung Cancer. New England Journal of Medicine, 371, 2167-2177. https://doi.org/10.1056/NEJMoa1408440

[21] Mazières, J., Zalcman, G., Crinò, L., Biondani, P., Barlesi, F., Filleron, T., Dingemans, A., Léna, H., Monnet, I., Rothschild, S., Cappuzzo, F., Besse, B., Thiberville, L., Rouvière, D., Dziadziuszko, R., Smit, E., Wolf, J., Spirig, C., Pecuchet, N., Leenders, F., Heuckmann, J., Diebold, J., Milia, J., Thomas, R. and Gautschi, O. (2015) Crizotinib Therapy for Advanced Lung Adenocarcinoma and a ROS1 Rearrangement: Results from the EUROS1 Cohort. Journal of Clinical Oncology, 33, 992-999. https://doi.org/10.1200/JCO.2014.58.3302

[22] Migita, T., Narita, T., Nomura, K., Miyagi, E., Inazuka, F., Matsuura, M., Ushijima, M., Mashima, T., Seimiya, H., Satoh, Y., Okumura, S., Nakagawa, K. and Ishikawa, Y. (2008) ATP Citrate Lyase: Activation and Therapeutic Implications in Non-Small Cell Lung Cancer. Cancer Research, 68, 8547-8554. https://doi.org/10.1158/0008-5472.CAN-08-1235

[23] Chen, Y., Li, K., Gong, D., Zhang, J., Li, Q., Zhao, G. and Lin, P. (2020) ACLY: A 
Biomarker of Recurrence in Breast Cancer. Pathology_Research and Practice, 216, Article ID: 153076. https://doi.org/10.1016/j.prp.2020.153076

[24] Sims, A., Howell, A., Howell, S. and Clarke, R. (2007) Origins of Breast Cancer Subtypes and Therapeutic Implications. Nature Clinical Practice Oncology, 4, 516-525. https://doi.org/10.1038/ncponc0908

[25] Hanash, S., Ostrin, E. and Fahrmann, J. (2018) Blood Based Biomarkers beyond Genomics for Lung Cancer Screening. Translational Lung Cancer Research, 7, 327-335. https://doi.org/10.21037/tlcr.2018.05.13

[26] Melosky, B., Blais, N., Cheema, P., Couture, C., Juergens, R., Kamel-Reid, S., Tsao, M., Wheatley-Price, P., Xu, Z. and Ionescu, D. (2018) Standardizing Biomarker Testing for Canadian Patients with Advanced Lung Cancer. Current Oncology, 25, 73. https://doi.org/10.3747/co.25.3867

[27] Lin, Y., Wu, J., Tseng, C., Chen, H. and Wang, L. (2018) Gjb4 Serves as a Novel Biomarker for Lung Cancer and Promotes Metastasis and Chemoresistance via Src Activation. Oncogene, 38, 822-837. https://doi.org/10.1038/s41388-018-0471-1 